\title{
Interpretación geológica de las leyendas del cerro o volcán Santa Lucía al oeste del valle de Ujarrás, Paraíso, Cartago, Costa Rica y su relación con los elementos particulares de su contexto fisiográfico
}

\section{Geological interpretation of the folk legends of the Santa Lucía peak/volcano west of the Ujarrás Valley, Paraíso, Cartago, Costa Rica, and its relationship with particular elements of its physiographic context}

\author{
Iván J. Sanabria-Coto ${ }^{1}$ \\ Investigador independiente, Costa Rica \\ Maureen A. Bonilla-Hidalgo ${ }^{2}$ \\ Instituto Costarricense de Electricidad, Costa Rica
}

\section{Resumen}

El área de estudio de esta investigación se ubica a $4 \mathrm{~km}$ al SE de la ciudad de Paraíso de Cartago y al oeste del Valle de Ujarrás, el objetivo fue el de proponer una interpretación geológica acerca de las leyendas recabadas en el libro de Prado (1921), denominado: "Nuestra Señora de la Virgen de Ujarrás" vinculadas con la aparente existencia y actividad del supuesto cerro o volcán Santa Lucía, también llamado: El Picacho. Para lo anterior fue necesario, inicialmente, una compilación de información histórica, y una recolección, en campo de evidencias particulares del contexto fisiográfico asociado; posteriormente se procedió a una análisis e integración de los resultados de las muestras recolectadas en campo; así como de los insumos geoespaciales necesarios para la confección de

1 Máster en Gestión de Recursos Naturales y Tecnologías de Producción del Instituto Tecnológico de Costa Rica. Licenciado en Geología de la Universidad de Costa Rica. Correo electrónico: isanac81@gmail.com (iD https://orcid.org/0000-0002-8281-298X

2 Licenciada en Geología de la Universidad de Costa Rica. Centro de Servicio Exploración Subterránea del Instituto Costarricense de Electricidad. Correo electrónico: MBonillaH@ice.go.cr (iD https://orcid.org/0000-0003-0680-626X 
los resultados. Se concluye que el tectonismo identificado en el área y sus posibles interacciones naturales permiten sustentar una interpretación geológica, de carácter no volcánico, sobre el posible origen de las leyendas vinculadas con el supuesto cerro o volcán Santa Lucía en el valle de Ujarrás.

Palabras Clave: volcán, cerro, Santa Lucía, Ujarrás, Costa Rica.

\begin{abstract}
The study area of the present investigation is located $4 \mathrm{~km}$ southeast of the city of Paraíso, de Cartago and west of the Ujarrás Valley, the objective was to propose a geological interpretation of the folk legends collected in Prado's book Nuestra Señora de la Virgen de Ujarrás (1921) (translated as Our Lady of the Virgin of Ujarrás) linked to the alleged existence and activity of a peak or volcano known as Santa Lucia or El Picacho. For this endeavor, it was initially necessary to perform a compilation of historical information as well as field collection of particular evidence of the associated physiographic context; next, field collected data and geospatial inputs were analyzed and integrated for the preparation of results. From the identified tectonism in the immediate geographical area and its possible natural interactions, it is feasible to support an assertive geological interpretation, of non-volcanic nature, regarding the origin of the folk legends in connection to the alleged existence of the Santa Lucia peak/volcano in the Ujarrás Valley.
\end{abstract}

Keywords: Santa Lucia peak/volcano; Ujarrás; Costa Rica.

\title{
Introducción
}

El presente trabajo se basa en una interpretación geológica de una serie de narraciones asociadas con las leyendas descritas por Prado (1921), sobre la existencia del cerro o volcán Santa Lucía, al oeste del valle de Ujarrás, Paraíso, Cartago y de su correlación con los elementos particulares que componen su contexto fisiográfico.

Las narraciones señalan el desarrollo de una serie de aparentes sucesos de origen natural, el mayor vinculado con una supuesta actividad volcánica; lo anterior, cuando la Villa de Ujarrás era un centro colonial ubicado al este de la ciudad de Cartago, dándose su traslado en el año 1832 a la Villa del Paraíso (ciudad de Paraíso). Seguidamente, se detallan los resultados de la compilación de la información, integración, análisis e interpretación geológica derivada de esta investigación.

\section{Área de estudio}

La zona de interés se localiza a 4 kilómetros al SE de Paraíso, Cartago (Figura 1), al oeste del antiguo emplazamiento colonial de la Villa de Ujarrás dentro del valle que preserva el mismo nombre. 
Iván J. Sanabria-Coto, Maureen A. Bonilla-Hidalgo

Interpretación geológica de las leyendas del cerro o volcán Santa Lucía al oeste del valle de Ujarrás,

Paraíso, Cartago, Costa Rica y su relación con los elementos particulares de su contexto fisiográfico

Figura 1. Área de interés ligada al supuesto cerro o volcán Santa Lucía, al SE del distrito central de Paraíso de Cartago y al extremo oeste del valle y poblado de Ujarrás.

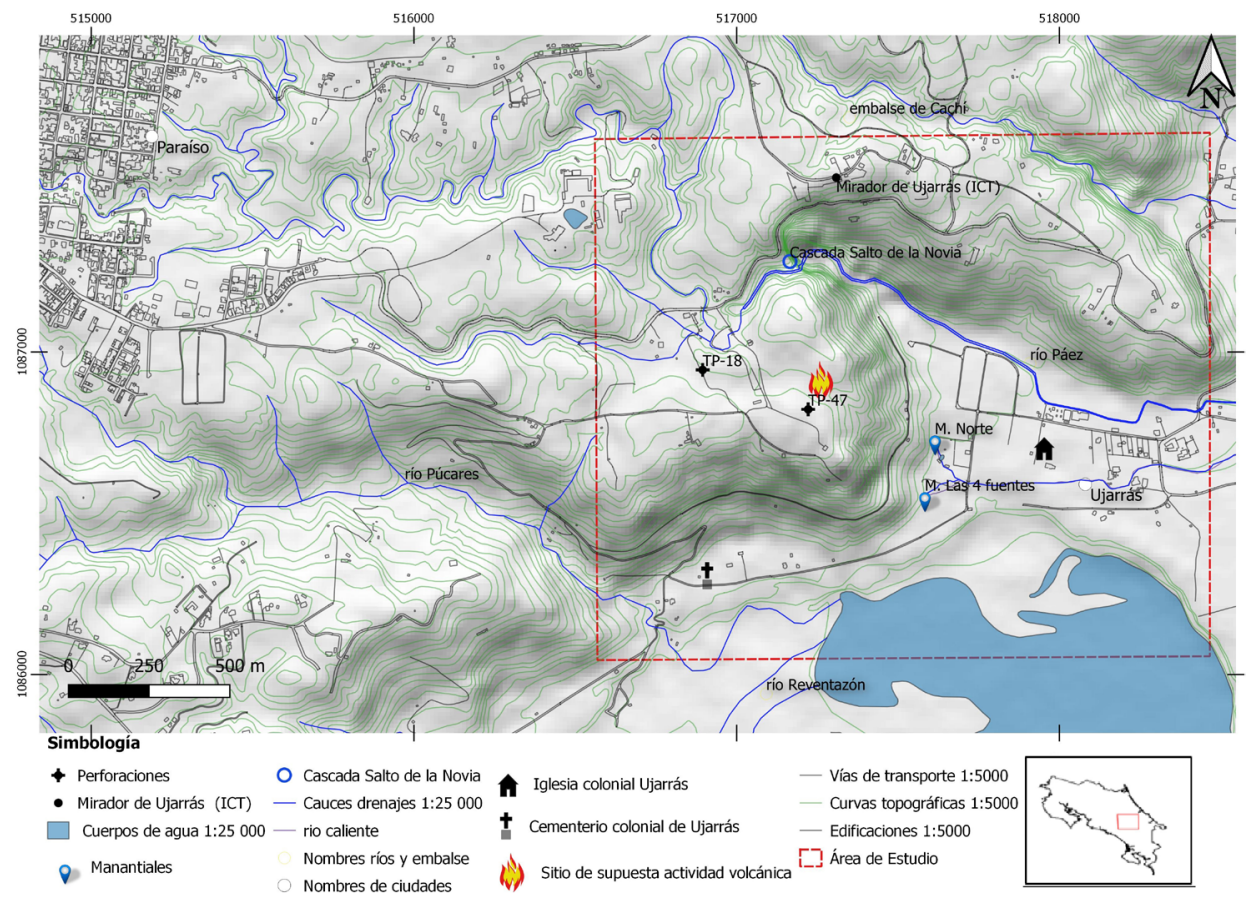

Fuentes: JAXA (2011), SNIT (2020) y elaboración propia.

\section{Características generales}

\section{Elementos geográficos e históricos importantes sobre la pobla- ción de Ujarrás}

Para Valenzuela (2011): "El valor geográfico de las leyendas no sólo consiste en que forman parte de la cultura, sino que la mayoría de las narraciones ocurren en un espacio localizable, como también son localizables algunas referencias naturales (ríos, montañas, lagos) o sociales (iglesias, plazas, calles), (...) a través de las leyendas mitológicas se explica el origen de los fenómenos naturales o de la formación del relieve, de los mares o de la flora y la fauna" (Valenzuela, 2011, pag.8).

Geográficamente el denominado cerro o volcán Santa Lucía por Prado (1921) y por una parte de los lugareños, se encuentra vinculado con un 
fuerte contraste topográfico propio del límite geográfico al oeste, noroeste y norte franco del valle de Ujarrás (Figura. 1).

De acuerdo con Mora (1998), durante las decadas de 1560 y 1570 se fundaron en la parte oriental del graben central del país: la ciudad de Cartago y las doctrinas indigenas de Cot, Quircot, Tobosi, Orosi, y Ujarrás; donde el plan estratégico era agrupar población indigena alrededor de un centro de dominación española, la fundacion de Ujarrás, como otros pueblos indigenas, tambien para Mora (1998) implicaba la coexistencia de un cura doctrinero y de un colonizador español, con lo cual en 1568 se asignó el repartimiento al Sargento Mayor Fransisco Destrada para la jurisdcción del "valle de Ujarraci".

Adiccionalmente según Mora (1998), esta ubicación geografica de Ujarrás determinaba que se trataba de un sector intermedio entre el territorio de dominio español, que abarcaba desde Cartago hasta los margenes del río Reventazón y las partes inferiores de la cordillera Talamanca que desde entonces ha permanecido bajo el dominio indigena hasta la actualidad.

Por otra parte, para Bolaños et al., (1993) el asentamiento colonial de Ujarrás se dio a partir del año 1570, tiempo en que los españoles forzaron a los naturales a quedarse allí fundándose allí la parroquia de Ujarrás. Por su parte Campos \& Orozco (2011), indican que dentro de la llamada Villa de Ujarrás los frailes franciscanos que vivían y trabajaban lograron establecer de forma "permanente" una misión religiosa para controlar a la población indígena existente en la zona a la llegada de los europeos.

También Campos \& Orozco (2011) indican que en el cuadrante central estaba la plaza que a la vez servía de mercado, en dirección este se encontraba la ermita, mientras que en dirección norte se localizaba la representación del gobierno español.

En la figura 2.a se aprecia un bosquejo cartográfico de Archivo Nacional de Costa Rica (ANCR), 2020) basado en el album de Figueroa de 1824, el cual muestra la aparente distribución de la antigua población del valle de Ujarrás, donde se incluye la existencia del supuesto cerro o volcán Santa Lucía (Figura 2.b). Por otra parte, hoy en día todavía conservan restos coloniales como el cementerio y las ruinas de la iglesia de la Virgen de Ujarrás construida, según Benavides (1999), entre 1680 y 1683 por el gobernador Miguel Gómez de Lara, siendo esta parte del patrimonio histórico costarricense (Figura 2.c). 
Figura 2. Bosquejo cartográfico de la Villa de Ujarrás en 1824 (2.a), en detalle visualización del supuesto cerro (2.b), y estado actual del templo colonial frente al supuesto cerro/volcán (2.c).
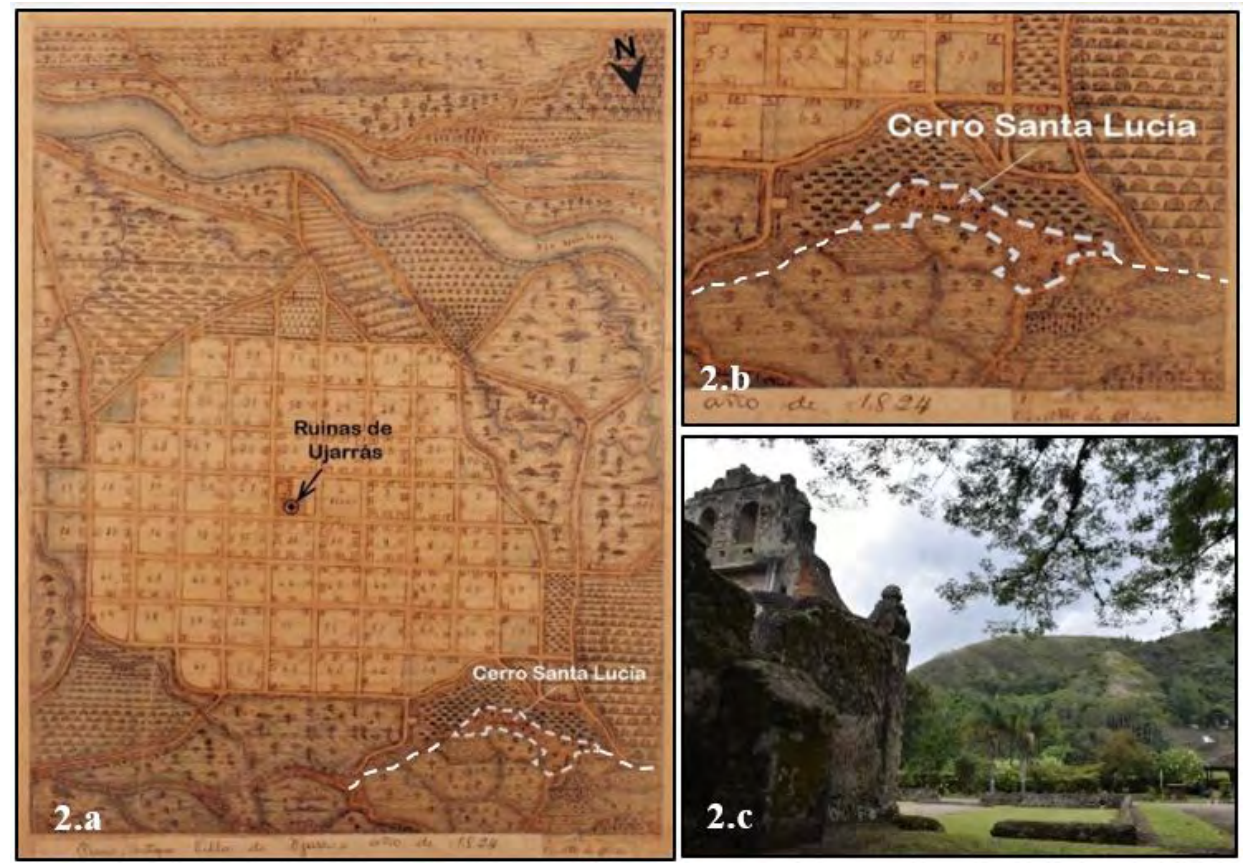

Fuente: ANCR (2020) y fotografía cortesía de Melina Sanabria.

Campos \& Orozco (2011), señalan que las características históricas y socio productivas en el valle de Ujarrás eran de una situación económica de pobreza casi generalizada, a pesar de existir personas con poder adquisitivo notable; sin embargo, la población de Ujarrás jugaba un papel importante, inclusive como un fortín oriental de la colonia española ya que desde allí se organizaron diversas campañas hacia la región de Talamanca.

Finalmente, Campos \& Orozco (2011) agregan que Ujarrás servía de defensa contra invasiones de piratas y zambos mosquitos hasta que posteriormente se dio el traslado de una buena parte de su población al actual Paraíso en el año 1832. 


\section{Marco teórico-conceptual \\ Valor geográfico y descripciones de las narraciones en la leyenda del cerro o volcán Santa Lucía}

Según la clasificación de Valenzuela (2011), las narraciones en la leyendas de Prado (1921), se pueden relacionar, mayoritariamente, con el tipo de leyendas de fenómenos y sucesos, donde esta categoría: proporciona o brinda una interpretación sobre diversos fenómenos astrales, celestes o naturales: eclipses, sucesión del día y la noche, cambio de estaciones, auroras boreales, tempestades, truenos, huracanes, erupciones volcánicas, sismos, inundaciones, entre otros (Valenzuela, 2011, p.12). Como parte de lo anterior se exponen, textualmente, los aspectos más importantes de las leyendas de Prado (1921), a continuación:

Terminando el valle de Ujarrás, hacia el oeste, se levanta un Cerro de poca vegetación y un tanto precipitado. Ese Cerro que aún hoy en día tiene en agitación constante la imaginación de los vecinos, los cuales afirman que para los terremotos de 1910, las fuentes que nacen en sus faldas corrían blancas como leche, y que, tanto antes como después de los terremotos, el Cerro, cuando menos piensa, se pone a bailar, tiene, pues, hacia la cumbre, un enorme hueco o concavidad, en el cual, si se echa a rodar una piedra, se oye por largo rato el ruido que hace al caer el ruido que va debilitándose poco a poco hasta escucharse como un eco muy lejano, que se pierde sin causar fondo alguno (Prado, 1921, p.17).

Este aspecto morfológico de una concavidad existente en la cumbre y de una profundidad desconocida también es mencionado en las narraciones, de algunas personas de la tercera edad, en el cantón de Paraíso; adicionalmente se indica que: El Cerro viene a ser como la última depresión, por ese lado, del gran macizo cuya cúspide domina el Irazú. (...) también me decían con cierta malicia un viejo descendiente de Ujarrás que me contó la historia en una de mis vistas a las pintorescas ruinas (...) que una mañana, cuando el Padre Guardián terminaba el santo sacrificio de la misa, al volverse al pueblo para dar la bendición, vio que el Cerro que esta frente a frente de una derruida iglesia, se alcanzaba en llamas (...) Muchos ujarraceños habian visto las llamas. Pronto estuvieron lo más con el Padre Cura. A medida que aumentaba el fuego, aumentaba el temor en las sencillas gentes. El Padre Guardián trato de tranquilizarlas, sin conseguirlo, proponiéndoles, entonces, subir con ellos al Cerro para bautizarlo, 
Iván J. Sanabria-Coto, Maureen A. Bonilla-Hidalgo

Interpretación geológica de las leyendas del cerro o volcán Santa Lucía al oeste del valle de Ujarrás,

Paraíso, Cartago, Costa Rica y su relación con los elementos particulares de su contexto fisiográfico

pues estaba sin cristianizar y no cabía duda de que a esto se debía su furor (Prado, 1921, p.17).

Además, sobre el nombre de volcán Santa Lucía, la narración señala que:

Se acercaron lo más que pudieron a las llamaradas (...) el Padre bendijo el Cerro en todas sus direcciones, empezando por el lugar de la erupción que roció bastante con agua bendita. En estos momentos el Cerro empezó a temblar que daba miedo y, tragándose las llamas reventó en cuatro fuentes. El Cerro, que también llaman volcán, recibió el nombre de Santa Lucía, porque en tal día se celebraba la fiesta de esta santa (Prado, 1921, p.17).

Un aspecto de mucho interés está asociado con las características físicas o de carácter organoléptico asociadas con las aguas manantiales ubicados en la base del supuesto cerro o volcán: Las fuentes son las quebradas de Ujarrás, llamadas también aguascalientes, aunque el agua que arrastra es fría, pero según el pensar de los vecinos, "son calientes al estómago" hacen daño según unos, y son medicinales según el sentir de otros. Yo las he tomado, son pesadas; el sabor que dan es amarroso, posiblemente deben contener mucho mineral. Son aguas cristalinas, pero son raros y contados los vecinos que toman de ellas por el miedo que les tienen (Prado, 1921, pp.17-18).

Adicionalmente Quirós (1981) señala que: “Chismosos y malas lenguas, decían que don Lorenzo había muerto de que ella, por celos, le dio a beber agua de "Las Cuatro Fuentes". Al pie del cerro desde el cual cae una catarata, brotan en diferentes lugares "Las Cuatro Fuentes", cuyas aguas, según los vecinos, son frías pero cálidas, porque, aunque, heladas, son calientes al estómago de quien las toma; y recogidas a cierta hora y de cierta manera, las aguas de Las Cuatro Fuentes resultan veneno mortal" (Quirós, 1981, p.26).

Para finalizar hay un dato histórico/geográfico particular expuesto por Benavides (1999), acerca de las acciones políticas y aparentes problemas que justificaron el proceso de traslado de la Villa de Ujarrás a la Villa del Paraíso en 1832, el cual se refiere a lo siguiente: "En el planteamiento del ejecutivo hay un dato nuevo que no se ha podido averiguar su procedencia ni cuál fue la fuente que lo respalda, pero ese dato sirvió como base para decir que el problema era causado por gases sulfúreos producidos 
por la no ventilación y por encontrarse la villa entre minerales. Lo que sí se aprecia es que fue un argumento contundente durante el proceso" (Benavides, 1999, p.159).

No obstante, se debe prestar atención en lo indicado por Benavides (1999), sobre las intenciones del traslado de los actores político/económicas de entonces, al señalar que "Para lograrlo manipularon la realidad acerca de los sucesos en Ujarrás y sobre las cualidades de los nuevos terrenos a que fueron trasladados" (Benavides, 1999, p.18).

\section{Marco metodológico}

El marco metodológico de la presente investigación comprendió en una primera etapa lo siguiente:

- Recopilación de insumos de percepción remota sobre la ubicación de caminos y senderos públicos para realizar el eventual trabajo de campo. Seguidamente se procedió al levantamiento de cortes del terreno con exposición de materiales geológicos en caminos, taludes naturales en ríos y quebradas con fines de observación y descripción de afloramientos de sedimentos y rocas.

- $\quad$ Posteriormente con la toma de muestras, para descripción macroscópica de campo, de rocas y sedimentos, así como de muestras para análisis de laboratorio (petrografía) usando varios senderos públicos de descenso al valle. Los cuales atraviesan toda el área geográfica de interés, para esto se dispuso a realizar un trayecto de campo (sendero A-Z), usando dos senderos públicos conocidos como: Del Picacho que desciende al valle y de la "La Palma" que comunica nuevamente la base del valle con el relieve superior hacia la ruta $\mathrm{N}^{\circ} 224$, que es la actual carretera a Ujarrás.

- $\quad$ Además, mediante botellas de polietileno de $500 \mathrm{ml}$ de alta densidad (HDPE), se dio la recolección de muestras de las aguas presentes en los manantiales ubicados en la base de supuesto cerro o volcán para efectos del estudio químico de laboratorio de sus iones mayoritarios principalmente como parte del proyecto de investigación en geotermia del Instituto Costarricense de Electricidad (ICE) durante los años 2007 a 2014. 
- Luego se realizó la caracterización fisicoquímica del agua de los manantiales, in situ, por medio de la medición de su temperatura, grado de acidez $(\mathrm{pH})$ y conductividad eléctrica, para tal efecto se utilizó un instrumento multiparamétrico portátil modelo WTW pH/Cond 340i, con un porcentaje de exactitud de $\pm 0.5 \%$.

- $\quad$ Por último, con los resultados del reporte de los iones mayoritarios en las aguas de los manantiales se procedió al uso de plantillas electrónicas tal como la denominada como "Liquid chemistry plotting spreadsheet versión 1", realizada por Powell \& Cumming (2010) y softwares libres para el procesamiento hidrogeoquímico como que es un software de uso libre, como "EASY_QUIM v.5.0" creado por Vázquez \& Serrano (2012).

En una segunda etapa se desarrolló una revisión exhaustiva de datos históricos asociados con el área geográfica de interés, los cuales pudieran brindar fundamentos históricos sobre detalles explícitos y adicionales a lo publicado por Prado (1921), en los registros históricos de las siguientes instituciones: Archivo Nacional de Costa Rica (ANCR), Biblioteca Nacional de Costa Rica, Biblioteca Municipal de Paraíso, Biblioteca Carlos Monge Alfaro de la Universidad de Costa Rica (UCR) y Biblioteca Luis Demetrio Tinoco de la UCR.

Sin embargo, cabe destacar que la obtención de información histórica sobre los supuestos sucesos naturales fue muy escasa a nula, este aspecto es reforzado por Brenes (2018), al señalar que la obra de Prado (1921), se concentra en la historia de la imagen de la Virgen de Ujarrás, las leyendas y milagros atribuidos, sin embargo, no se problematiza acerca de los datos que presenta ni indica sus fuentes para sustentar la información que expone.

Así mismo el historiador M. Benavides indica que: "las fuentes históricas que quedan sobre Ujarrás y Paraíso de la primera mitad del siglo XIX hacia atrás están muy dispersas, y el problema del pueblo de Ujarrás es que no tiene continuidad histórica a nivel demográfico, pues la población original desapareció por la viruela a finales del siglo XVII" (comunicación personal, 23 de junio, 2020).

Por estas razones, es que no se aportan mayores detalles históricos que puedan dar registro de tales eventos señalados en las narraciones de 
Prado (1921) o que directamente describan la relación entre la población y el denominado cerro/volcán Santa Lucía. Finalmente, en una tercera etapa se procedió con la recolección, clasificación y análisis de insumos de percepción remota la cual incluyo:

- $\quad$ La búsqueda y compilación de información geoespacial, formato ráster y vectorial, en repositorios tanto nacionales como internacionales y la recopilación de estudios tectónicos asociados al fallamiento tectónico comprobado y/o inferido. Además de la revisión de estudios geológicos/geomorfológicos y compra de información de pozos de agua (TP-47) en el Servicio Nacional de Aguas Subterráneas Riego y Avenamiento (SENARA).

- $\quad$ Finalizado todo lo anterior, se procedió a la etapa final de integración sistemática de la información geoespacial usando el software libre en Sistemas de Información Geográfica denominado como: QGIS, para su respectivo análisis y consecuente confección los resultados, discusión y conclusiones obtenidas dentro de la presente investigación.

\section{Resultados}

\section{Principales características geomorfológicas y tectónicas del área de interés}

El área de estudio presenta una fuerte geodinámica interna y externa que es reflejada por diferentes evidencias geomorfológicas de origen volcánico y tectónicas (Figura 3).

La clasificación de las principales características geomorfológicas del área, están basadas en Zuidam (1986), ligadas principalmente con el control estructural o fallamiento tectónico local del relieve, también con el resultado de geoformas producto de una actividad volcánica, de un origen muy distal, tal como Sojo et al., (2017) y por Krushensky (1972) describen y con aspectos geomorfológicos observados por Bergoeing \& Malavassi (1981a, b).

Adicionalmente en el área de estudio se evidencian fuertes procesos de erosión y sedimentación como resultado de la hidrodinámica fluvial local activa (F1) en el contraste de los relieves topográficos, mismos que son mayormente representados por el río Reventazón en su tránsito sobre la planicie de inundación que lleva al embalse de Cachí. También por la 
Figura 3. Mapa geomorfológico asociado con el área de interés

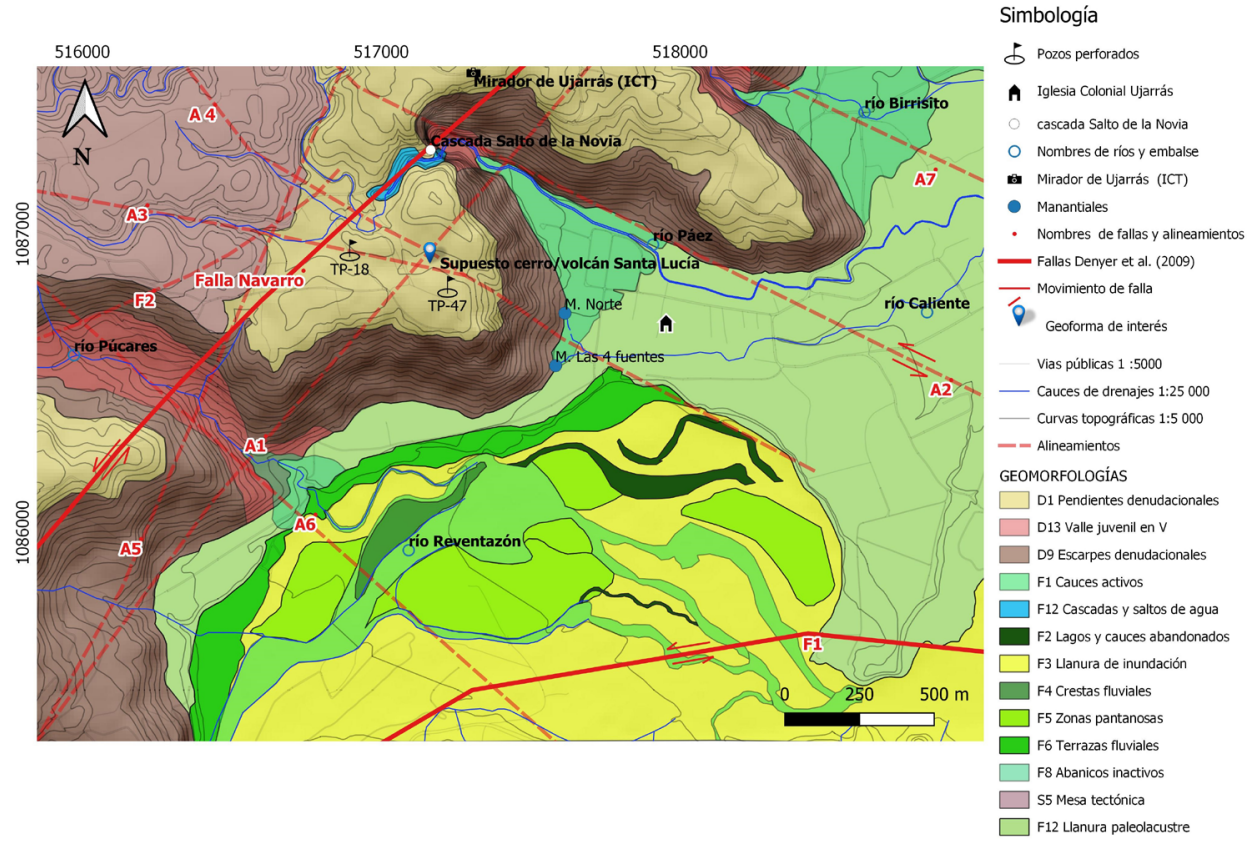

Fuentes: Bergoeing \& Malavassi (1981a, b), Denyer et al. (2009) JAXA (2011), Sojo et al. (2017), SNIT (2020) y elaboración propia.

formación de terrazas fluviales producto en parte del socavamiento de la llanura superior paleo-lacustre (F13), que existió en el valle, así como de la presencia de zonas pantanosas (F5), lagos y cauces abandonados (F2), así como crestas fluviales (F4) observables en la figura 3.

Los procesos erosivos/sedimentarios se relacionan también con las geomorfologías propias de los ríos Púcares, Páez y Birrisito caracterizados por estrechos valles juveniles, en forma de $\mathrm{V}$, con sus respectivos alineamientos: A6, A2 y A7, además de la presencia de cascadas de agua (F12) como la cascada Salto de la Novia, y sus consecuentes abanicos coluviales actualmente inactivos (F8) como parte de la transición del relieve hacia el fondo del valle (Figura.3).

Debido a todo lo anterior, la geoforma aislada mencionada en las leyendas de Prado (1921), ha sido confundida con una morfología de un aparente cerro o cono volcánico (Figura.1), la cual realmente en la figura 3, se visualiza como un relieve caracterizado por pendientes y escarpes denudaciones: D1 y 
D9 respectivamente, asociados directamente por Krushensky (1972) con la unidad superior de la formación geológica Reventado.

El evidente escarpe denudacional (D9), el cual conforma un alto porcentaje de la aparente geoforma cónica del cerro/volcán Santa Lucía, se encuentra asociado con un frente de rocas de lava volcánica que se levantan casi $200 \mathrm{~m}$ desde del fondo del valle; conservando una homogeneidad e integridad lateral de la pendiente, fuera de la aparente geoforma, al suroeste, noroeste y al norte del valle de Ujarrás (Figuras 3 y 4.a).

Figura 4. Alineamiento tectónico A1 y la traza de la falla Navarro (F.N) en el aparente cerro/volcán Santa Lucía (4.a), ubicación de las ruinas del templo colonial de Ujarrás (4.b) y la perforación del pozo PT-47 durante el año 2010 (4.c).

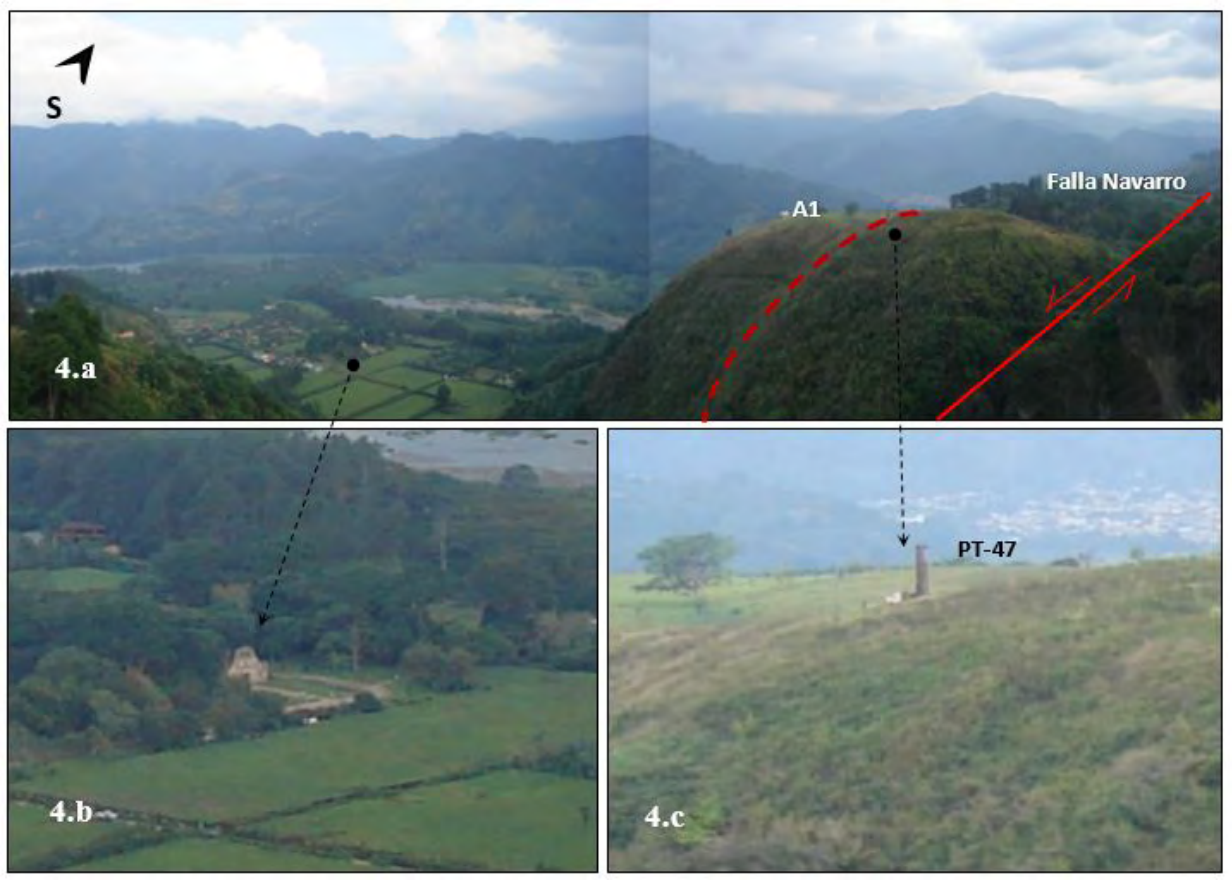

Fuente: Elaboración propia.

La morfología D9, presenta un fuerte contraste de topográfico superior del escarpe respecto tanto a la llanura paleo-lacustre (antiguo lago) y a la planicie de inundación actualmente activa estando asociada con el 
patrón meándrico del río Reventazón en su paso a el embalse de Cachí como se aprecia en la figura 3.

Cabe destacar que esta morfología D9 es afectada por posibles fallas tectónicas que se presentan como alineamientos topográficos del relieve (A5, A1 y F2), con rumbos: noreste/suroeste, siendo el más importante el asociado con la traza de la falla Navarro (F.N) o también denominado Sistema de Fallas Navarro (Montero et al., 2016). Estos alineamientos están caracterizados por fuertes disectaciones del terreno, que han sido potenciados por la meteorización y continua erosión.

Adicionalmente con una orientación casi perpendicular se encuentran los alineamientos tectónicos: A6 y A2 con direcciones: sureste/noroeste, los cuales están ligados con los valles juveniles de los ríos Púcares y Páez respectivamente. En definitiva, todos estos elementos geomorfológicos/tectónicos, en su conjunto, propician en el relieve resultante una aparente geoforma aislada que observada desde varios sitios, especialmente del fondo del valle, parece ser de tipo cónica con una depresión cuspidal, derivada de los procesos tectónicos (alineamientos A3 y A4) y erosivos antes mencionados, pero que ha sido erróneamente interpretada como un cráter.

\section{Principales características geológicas asociadas con el área de interés}

Como resultado de los estudios de cartografiado, informes geológicos, descripciones de perforaciones de pozos y de los resultados del trabajo de campo (perfil de muestreo A-Z), se logró conformar el siguiente mapa geológico local para el área de estudio (Figura 5) con especial énfasis en el sector del supuesto cerro/volcán Santa Lucía. 
Figura. 5. Mapa geológico del área de estudio

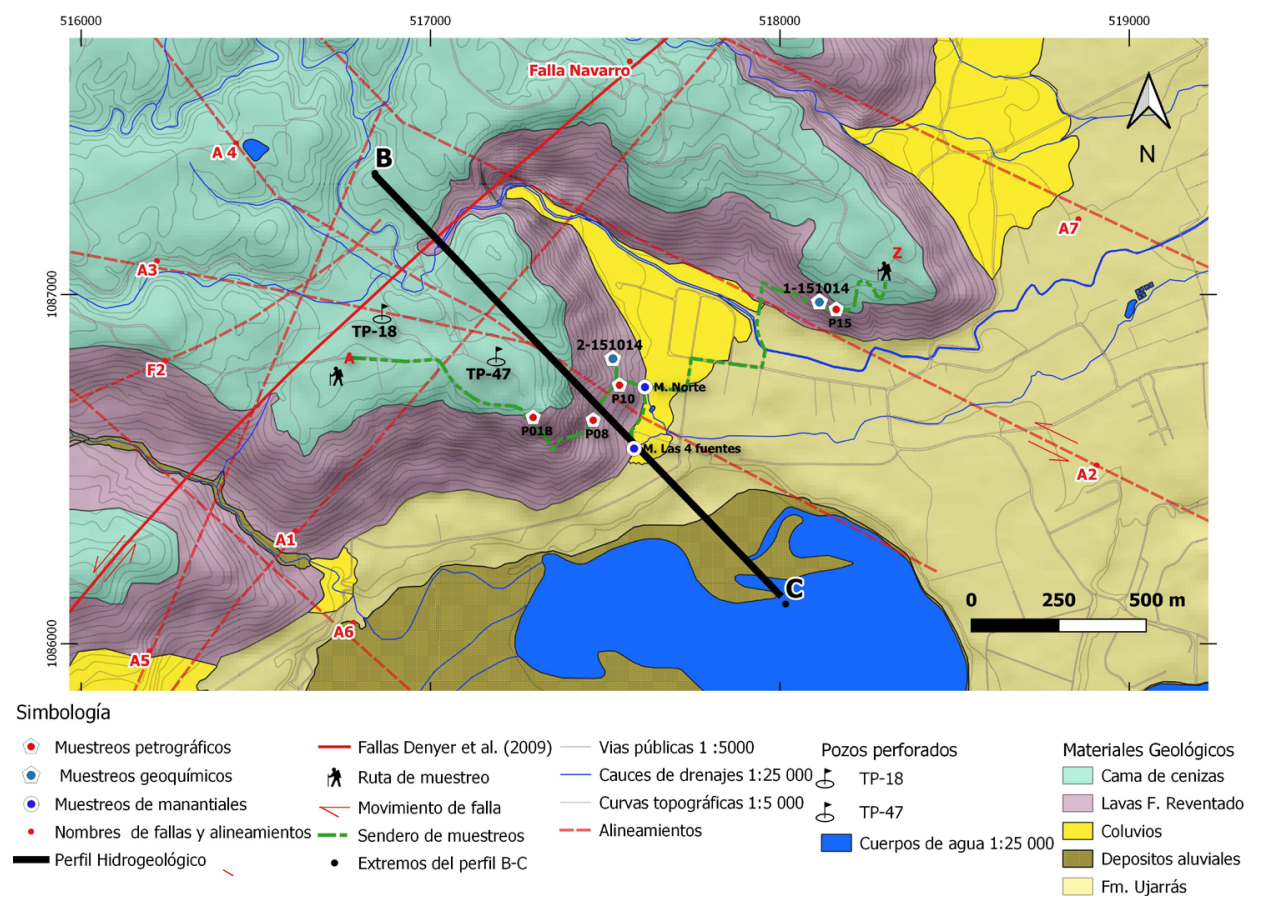

Fuente: Krushensky (1972), Denyer et al. (2009), Sojo et al., (2017) y elaboración propia.

En el mapa geológico local de la figura 5, se describen las siguientes formaciones del área de estudio asociada al aparente cerro/volcán Santa Lucía:

- Cenizas café rojizas de la formación Reventado

Estos materiales denominados por Krushensky (1972), como cama de cenizas meteorizadas, son observables dentro de la Figura.5 en la parte superior del denominado cerro o volcán Santa Lucía (Figura. 6.a), siendo caracterizados por cenizas color café/rojiza de texturas medias a gruesa, con espesores métricos no superior a $20 \mathrm{~m}$ aprox; las cuales poseen una continuidad geográfica lateral en otros puntos geográficos en la localidad de Paraíso (Dondoli \& Torres, 1954, Krushensky; 1972). No obstante, para Sojo et al., (2017) y Sojo (2018) son interpretadas como posibles frentes de meteorización de las lavas subyacentes (Figura.6.b) propias de la 
formación Reventado (Miembro Paraíso), denominándolas como: Capa de Laterita El Rincón, siendo un término que engloba la ubicación de la localidad tipo y el material (Sojo, 2018).

Figura 6. Cenizas rojas en la parte superior del denominado cerro Santa Lucía, al fondo el río Reventazón, (6.a) y las lavas sanas y fracturadas subyacentes que componen gran parte de la aparente geoforma cónica (6.b).
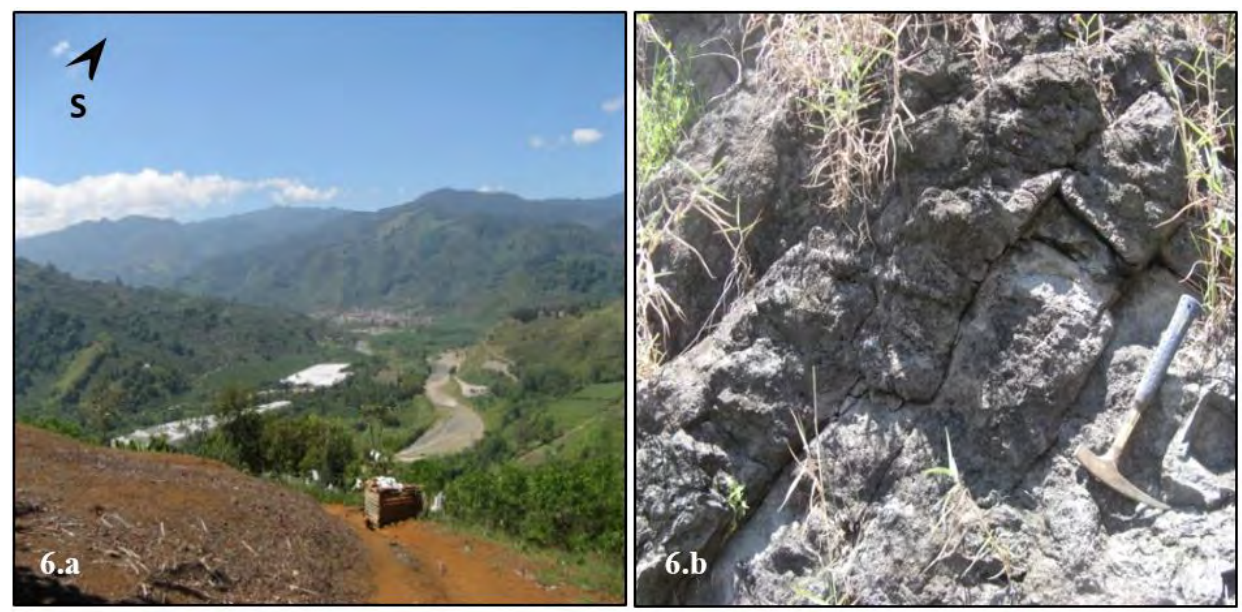

Fuente: Elaboración propia durante trabajo de campo.

- $\quad$ Lavas del Miembro Paraíso (Formación Reventado)

Conforme se desciende por el sendero denominado Del Picacho, y asociado con el perfil de muestreo A-Z (Figura 5), las anteriores cenizas dan paso a numerosos afloramientos rocosos, siempre con diferentes grados de fracturamiento, compuestos por rocas volcánicas (lavas), con espesores decamétricos masivos siendo relativamente meteorizadas a bastante sanas (Figura.6.b), estas se encuentran asociadas directamente con el Miembro Paraíso de la Formación Reventado (Krushensky, 1972), teniendo composiciones andesíticas/basálticas masivas (Krushensky; 1972 \& Sojo et al. 2017).

Mediante la recolección de muestras de roca P01B, P08, P10 y P15 y los respectivos resultados petrográficos (Figura 7), obtenidos por Barrantes (2011) se deduce su correspondencia geoespacial, con la geomorfología de 
escarpe (D9) de las figuras 3 y 4, además que existe una evidente correlación litológica entre sí con las lavas del Miembro Paraíso (Krushensky, 1972), para todos los afloramientos rocosos a lo largo del descenso del sendero de muestreo A-Z (Figura 5).

Figura 7. Resultados generales en los porcentajes texturales para las muestras petrográficas analizadas por Barrantes (2011).

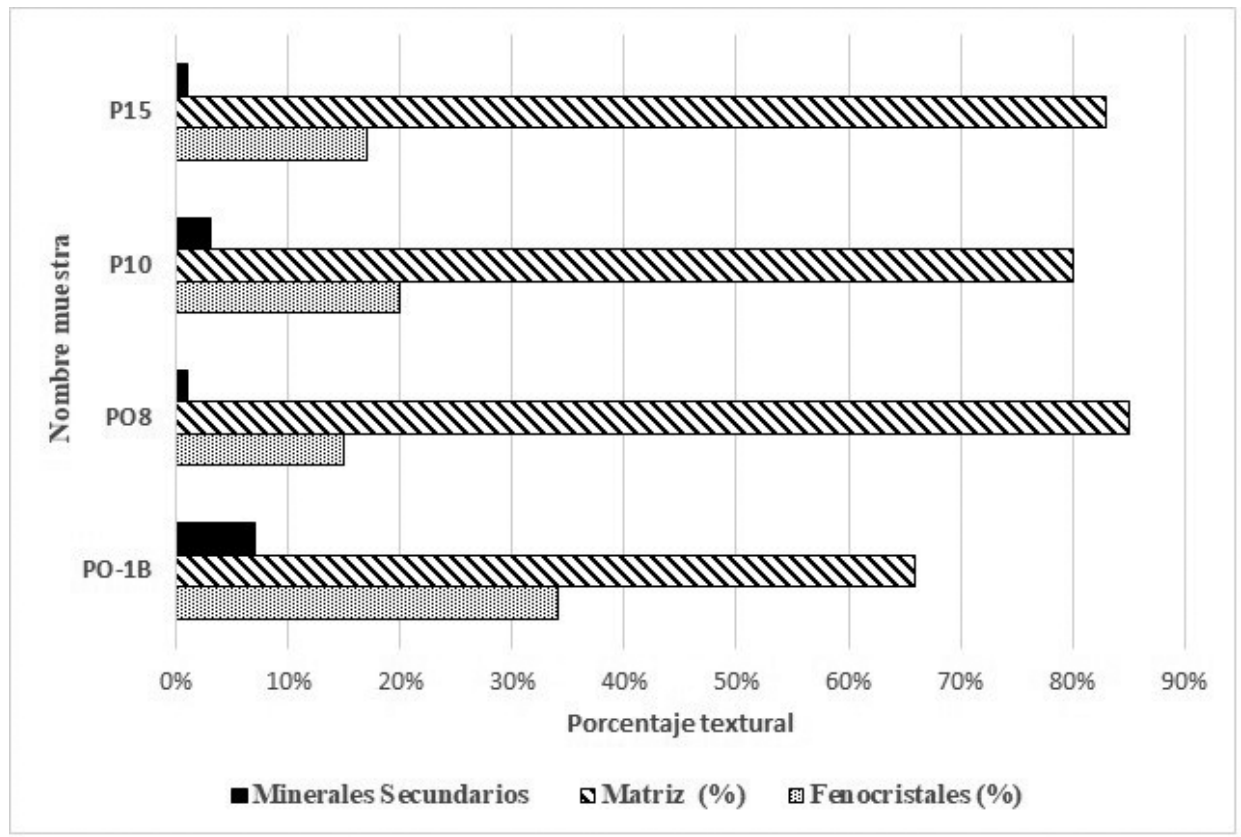

Fuente: Elaboración propia con base en resultados petrográficos de Barrantes (2011).

Según los resultados de Barrantes (2011), los nombres petrográficos asociados para todas las muestras de roca analizadas corresponden con andesitas/basálticas, solo en el caso de la muestra P0-1B, se hace la leve diferenciación textural por andesita/basáltica con dos piroxenos.

Lo anterior permite una correlación geoespacial (textural y composicional) de las lavas del Miembro Paraíso, de un origen distal, con estas muestras asociadas al aparente cerro/volcán Santa Lucía, así como con otros sectores geográficos y de alto relieve topográfico circundantes al valle específicamente al oeste y norte de ese lugar, evidenciado con la muestra de roca P15 y las muestra geoquímicas: 2-151014 y 1-151014 de 
Sojo et al., (2017). Con todo esto se descarta una composición litológica diferente, especifica o propia de una posible actividad volcánica "in situ" en la formación o construcción de la aparente geoforma volcánica aislada descrita por Prado (1921).

Sumado a lo anterior y como parte del análisis de los resultados Barrantes (2011), se infiere (Figura 8), la similitud composicional en el porcentaje de fenocristales entre las muestras de roca obtenidas en el sendero Del Picacho para las muestras: P0-1B, P08, P10 ubicadas en la aparente geoforma volcánica, así como al norte de esta en el sendero "De la Palma" (muestra: P15), ambas rutas pertenecientes al sendero de muestreo A-Z (Figura 5).

Figura 8. Análisis sobre los resultados generales de los porcentajes mineralógicos composicionales en los fenocristales para las muestras petrográficas analizadas.

$\%$ Fenocristales vs Minerales

20

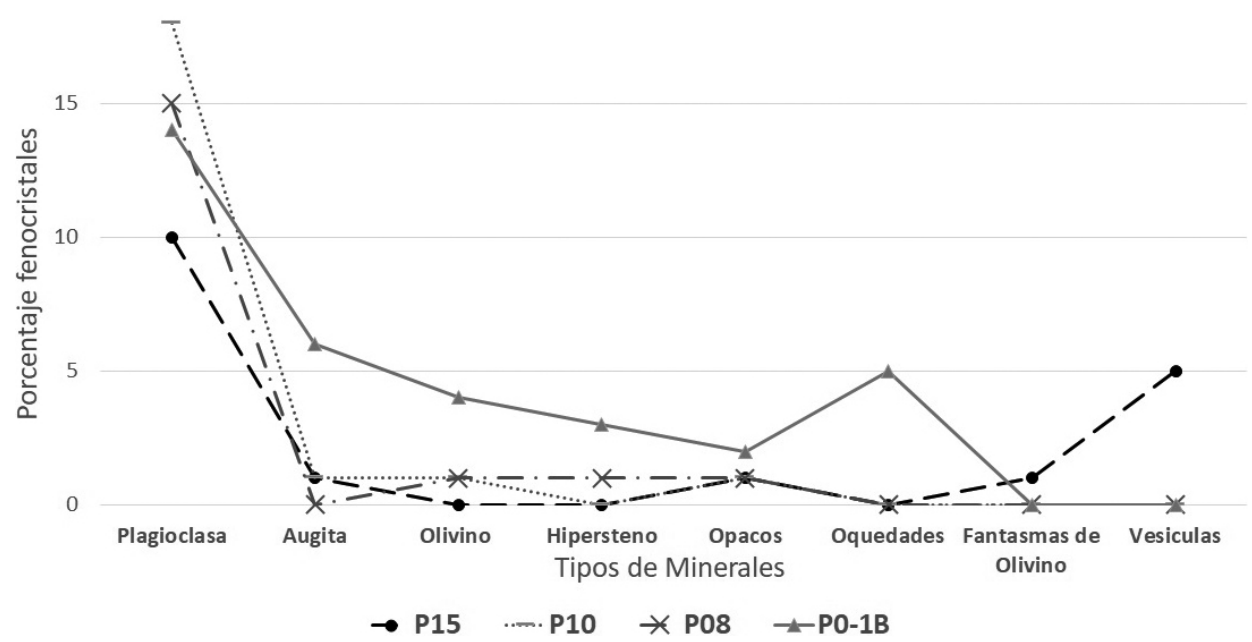

Fuente: Elaboración propia con base en resultados petrográficos de Barrantes (2011).

- Depósitos coluvio/aluviales y fluvio lacustres en la base del denominado cerro/volcán Santa Lucía

En la base del supuesto cerro, se verifica la existencia de materiales de naturaleza coluvial producto de la meteorización, erosión y respectiva 
acumulación de las lavas superiores, con presencia de clastos de roca angulares centimetricos a métricos que conforman un perfil de transición topográfica al sector plano (piso del valle).

Adicionalmente, en el sector topográficamente plano, se presentan características fluvio/lacustres, de bloques de conglomerados decimétricos en contactos flotantes dentro de una matriz de arena gruesa, conformado los depósitos paleo lacustres de la Formación Ujarrás y en los cauces fluviales activos se da la presencia de depósitos aluviales cuaternarios o recientes observados durante el trabajo de campo y previamente por Krushensky (1972) así como Montero et al., (2016).

Finalmente, cabe señalar, que en el respectivo informe de perforación de Chaves (2010) para el pozo: código TP-47 (Figuras 4 y 5) ubicado en la parte superior del aparente cerro/volcán Santa Lucía y con una profundidad de $220 \mathrm{~m}$, se describen una serie de litologías que guardan una estrecha relación con las observaciones geológicas de campo realizadas durante esta investigación. No obstante, Un aspecto de bastante interés es que Chaves (2010), indica textualmente, que durante la perforación en el sitio denominado como cerro o volcán Santa Lucía: "A los 78 m de perforación, se presentó una gran fractura o caverna, lo que impidió que la salida del material que se perforó, se presume la continuidad de estas lavas" (Chaves, 2010, p.3).

\section{Características hidrogeoquímicas e hidrogeológicas asociadas al área estudio}

En mediciones de campo realizadas, a mediados del año 2012, mediante un instrumento multiparamétrico portátil, en los manantiales: norte y de Las Cuatro Fuentes, se observaron temperaturas de $23,9^{\circ} \mathrm{C}$, y $25,7^{\circ} \mathrm{C}$ respectivamente.

De acuerdo con Ortiz \& Montoya (2014) la temperatura promedio anual para la estación meteorológica más cercana a $4 \mathrm{~km}$ al este aprox. (plantel del ICE en Cachí), es de $20,2^{\circ} \mathrm{C}$ entre los años 1973 al 2001; por lo cual se logra inferir, según la clasificación de Schoeller (1962), que las aguas del manantial norte se catalogan , preliminarmente, como aguas frías; no obstante, las del manantial llamado "Las Cuatro Fuentes" son clasificables como aguas levemente termales, siendo casualmente este último 
manantial, uno de los que aporta un considerable caudal para la conformación del llamado "río Caliente".

Adicionalmente, para un periodo de observación que abarcó desde el año 2009 (figura 9.a) hasta el año 2012 (figura 9.b), se pudieron apreciar cambios en la coloración de las aguas de los manantiales, especialmente en el manantial norte con la coloración blanquecina asociada a una aparente sustancia disuelta (liquida y/o gaseosa).

Figura 9. Condiciones observadas en manantial norte en el año 2009(9.a) y en el año 2012(9.b).
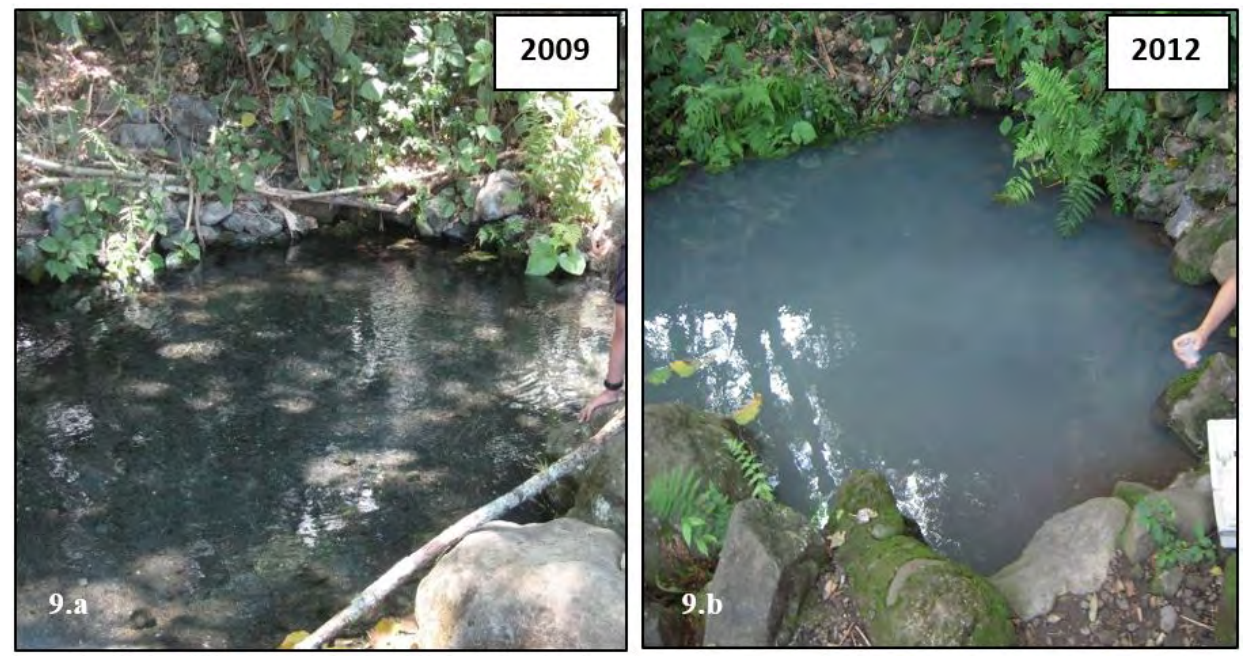

Fuente: Elaboración propia durante trabajo de campo entre los años 2009 y 2012.

A la convergencia de caudales de las aguas de ambos manantiales: norte y de "Las Cuatro Fuentes", se les denomina como: "río Caliente" por parte de los pobladores y por Prado (1921), el cual discurre a $100 \mathrm{~m}$ aprox. al sur de la antigua iglesia colonial de Ujarrás (Figura 1 y 3 ).

Adicionalmente mediante la interpretación de resultados para los iones mayoritarios de los análisis de aguas en ICE (2011-2012) de las muestras: Las Cuatro Fuentes (muestra BE-42b) y el norte (muestras: BE-42 y BE-40b), se obtiene un primer diagrama de tipo Piper (Figura. 10.a), mismo que según Custodio \& Llamas (2001), permite observar que las aguas geoquímicamente similares quedan agrupadas en áreas bien definidas; por 
otra parte mediante un segundo diagrama de tipo ternario (Figura 10.b) de iones de $\mathrm{Cl}^{-}, \mathrm{SO}^{2-}$ y $\mathrm{HCO}^{3-}$ (Giggenbach, 1988; Giggenbach \& Goguel, 1989), se puede ubicar las muestras dentro de un posible sistema geotermal/volcánico posiblemente distal, ya que la cantidad relativa de estos componentes varían con la evolución de las aguas en dicho sistema.

En los gráficos asociados con el análisis de los resultados de ICE (2011-2012) para las aguas los manantiales en la base del aparente cerro/ volcán Santa Lucía, se infiere dentro de la figura 10.a, que ambos manantiales pertenecen a un mismo sistema acuífero subterráneo, vinculados al grupo de las aguas Bicarbonatadas Magnésico-Cálcicas (Custodio \& Llamas, 2001), las cuales denotan la presencia de aguas superficiales, posiblemente de origen meteórico y/o de aportes influentes al acuífero (ríos), con una poca evolución o de circuito subterráneo corto de acuerdo con la secuencia de Chebotarev, desde su infiltración en superficie hasta su salida en los precitados manantiales.

Por otra parte, dentro el gráfico ternario de $\mathrm{Cl}^{-}, \mathrm{SO}^{2-}$ y $\mathrm{HCO}^{3} \mathrm{de}$ la figura $10 \mathrm{~b}$, se aprecia un comportamiento hidrogeoquímico propio de aguas superficiales y/o meteóricas, dentro de un posible sistema geotérmico distal a el área, caracterizado por una leve influencia química, mezcla o tendencia sulfatada $(<20 \%)$, lo cual es correspondiente con los rangos de las conductividades eléctricas y de acidez $(\mathrm{pH})$ de 200-206 $\mu \mathrm{s} / \mathrm{cm}$ y de 6,52-7,76 obtenidos respectivamente para las muestras de agua en ambos manantiales.

Una de las razones de los posibles aportes sulfatados observados las aguas, puede deberse a la mezcla resultante entre el acuífero formador de los manantiales mayoritariamente de aguas superficiales y/o meteóricas más el aporte leve o difuso de líquidos o gases de orígenes geotérmicos profundos y/o lejanos (Figura 11). 
Iván J. Sanabria-Coto, Maureen A. Bonilla-Hidalgo

Interpretación geológica de las leyendas del cerro o volcán Santa Lucía al oeste del valle de Ujarrás, Paraíso, Cartago, Costa Rica y su relación con los elementos particulares de su contexto fisiográfico

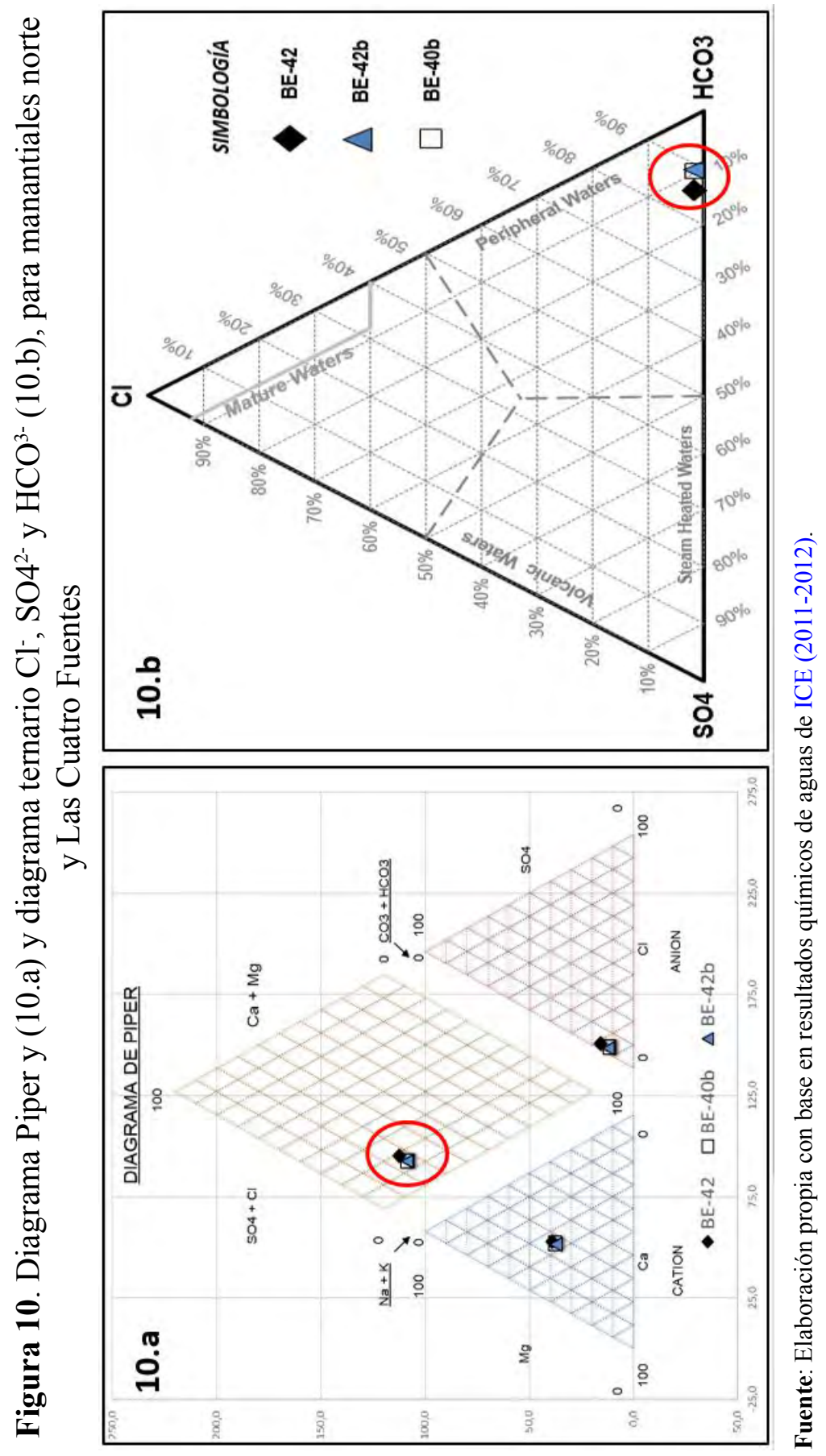


Figura.11. Modelo hidrogeológico conceptual del perfil B-C ubicado en la Figura. 5.

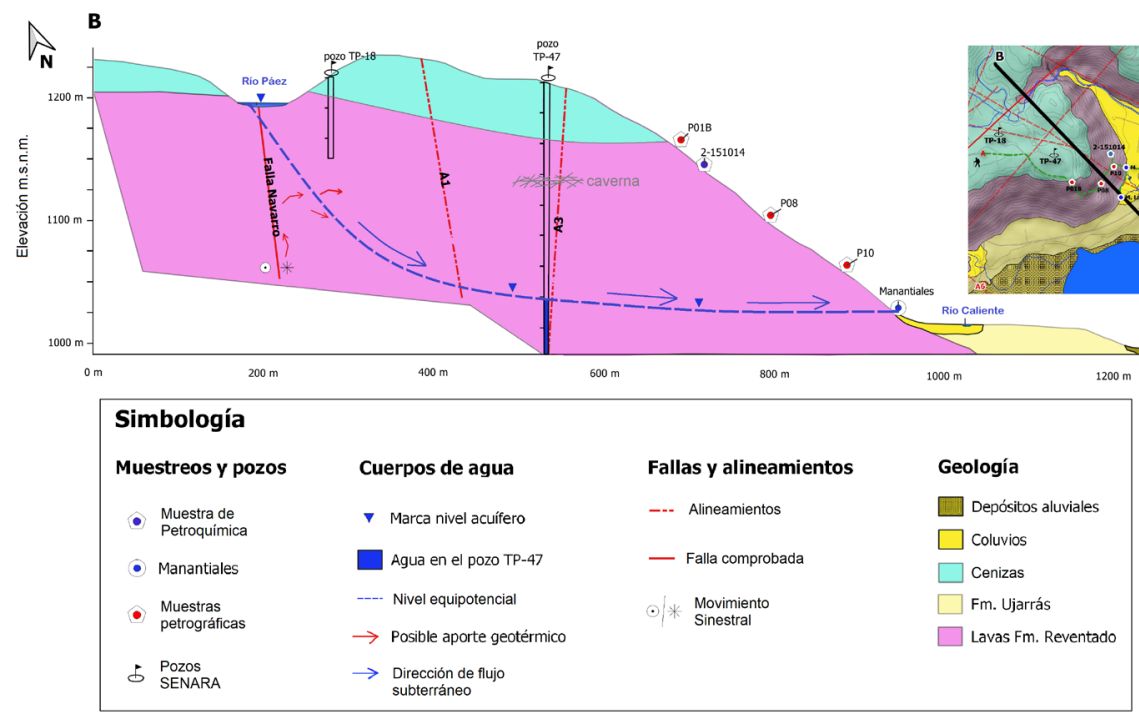

Fuente: Elaboración propia.

Por lo tanto y de acuerdo con la teoría expuesta por Nicholson (1993), se logra interpretar el comportamiento hidrogeoquímico del manantial de "Las Cuatro Fuentes", como propio del resultado de la circulación de aguas meteóricas o superficiales que han infiltrado en los márgenes de un posible sistema geotérmico existente, evidenciando una posible interacción distal del mismo con aportes de quimismo y temperatura, lo cual re representa en el perfil hidrogeológico conceptual (Figura.11).

\section{Discusión}

\section{Materiales geológicos asociados con la formación del aparente cerro/volcán Santa Lucía}

Se concluye que los materiales geológicos observados en la conformación geológica del supuesto cerro/volcán Santa Lucía se vinculan directamente con la existencia de litologías geológicas regionales, previamente definidas y cartografiadas por Krushensky (1972) como Miembro Cama de Ceniza y las lavas del Miembro Paraíso; ambas pertenecientes a la Formación Reventado, mismas que tiempos recientes han tenido algunas 
redefiniciones por parte de Sojo et al., (2017) y Sojo (2018); no obstante, por sus características macroscópicas, petrográficas y geoquímicas son claramente identificables en otros sectores del área de estudio, fuera de la aparente geoforma volcánica.

La Formación Reventado guarda un carácter regional y representativo directamente en el sitio de interés (Sojo, 2018); por lo que no fue posible observar considerables espesores de otros materiales de índole volcánico que fueran, geológicamente, más recientes a las fechas definidas por Sojo et al., (2017) en el orden 0.6 Ma, para las lavas fracturadas del Miembro Paraíso, siendo estas preponderantes en la formación del supuesto cerro/ volcán Santa Lucía. Todo lo anterior permite descartar una local y reciente expulsión así como consecuente acumulación de materiales volcánicos poco consolidados, derivados un foco eruptivo dentro del área de estudio, además de pocas evidencias de diferentes grados de hidrotermalismo en los materiales existentes por una fuente de calor "in situ".

Sumado a lo anterior se encuentran los resultados de las muestras petrográficas de roca: P0-1B, P8, P10 analizadas por Barrantes (2011), las cuales revelan una correlación mineralógica/textural y geoespacial entre sí; permitiendo correlaciones con materiales geológicos (lavas) fuera de la aparente geoforma de cerro/volcán Santa Lucía, específicamente al norte del área de estudio, tal como lo revela la muestra petrográfica P15 analizada por Barrantes (2011), así como las correlaciones geoquímicas derivadas de Sojo et al., (2017) entre las muestras: 2-151014 ubicada en la base de la aparente geoforma del cerro/volcán Santa Lucía y la muestra 1-151014 al norte de la misma.

\section{Características geomorfológicas asociadas al tectonismo en el área de estudio del cerro/volcán Santa Lucía}

Por otra parte, con el respectivo análisis de percepción remota, no se identificaron elementos geomorfológicos propios de una estructura o cuerpo cónico asociado con el supuesto cerro o volcán Santa Lucía, tales como patrones hídricos locales de carácter radial mencionados por Obando, (2004), los cuales se podrían asociar con una morfología de cráter monogenético o bien del tipo "cono de ceniza o escoria". Tampoco se logró corroborar características morfométricas volcánicas cónicas básicas y bien definidas; tales como las descritas por Bemis et al., (2011) sobre: diámetro 
basal, altura, y su diámetro superior o bien del tipo morfométrico volcánico señalado por Villa (2013).

En contraposición se aprecia que la seudogeoforma cónica asociada con el supuesto cerro o volcán Santa Lucía, es resultado o producto directo de la disectación del relieve y materiales circundantes (Formación Reventado), por diferentes alineamientos y fallas tectónicas (Figuras 3, 4.a y 5) propias del contexto geomorfológico local, principalmente, al norte y sur del denominado cerro o volcán Santa Lucía las cuales sumadas a los procesos de meteorización erosión han propiciado una delimitación lateral del frente de las geomorfologías denudacionales D1 y sobretodo de escarpe (D9) que asemejan un cerro aislado o una seudoforma volcánica con características cónicas y/o cratéricas.

\section{Condiciones tectónicas y su relación con características hidro- geológicas e hidrogeoquímicas en el área de estudio del cerro/ volcán Santa Lucía}

Todas las estructuras tectónicas (fallas) comprobadas e inferidas como alineamientos en el área de estudio, contribuyen en menor o mayor medida con sus esfuerzos y deformación, a la aparición de amplias zonas de interacción y fracturamiento sobre la roca, provocando el daño de los materiales geológicos existentes e implicando la formación de grietas o fracturas, que sumadas al flujo de aguas subterráneas y su erosión pueden facilitar la formación de amplios sectores de permeabilidad acuífera $(\mathrm{Cu}-$ rewitz \& Karson, 1997).

Lo anterior puede facilitar la conformación de pasos o flujos de agua complejamente interconectados hasta la formación de posibles cavernas, las cuales podrían tener dimensiones desconocidas en la profundidad del aparente cerro/volcán tal como se evidencio con la perforación TP-47 (Figuras 4.c y 11), favoreciendo la acumulación y el flujo de las aguas subterráneas; así como la formación de manantiales específicamente debido al fuerte contraste topográfico del valle (Figura 12).

Por otra parte, los cambios de tonalidad de tipo blanquecinas o "lechosas" observadas y semejantes a una sustancia (liquida o gaseosa) disuelta en las aguas del manantial norte, durante una visita al campo en el año 2012, concuerdan con lo mencionado en relatos de Prado (1921), así como con los relatos verbales de pobladores del valle de Ujarrás, los 
cuales los han relacionado con fuertes periodos lluviosos en el área y/o de actividad sísmica.

No obstante, cabe señalar que estos cambios reportados, no son un fenómeno aislado de esta área, ya que autores como González (1910), Linkimer (2002) previamente han mencionado situaciones similares después de una fuerte actividad sísmica, con cambios en las coloraciones en manantiales, quebradas, ríos y hasta existe un caso documentado por Vargas (2016) con cambios en el comportamiento hidrogeológico de acuíferos seguidamente a eventos sísmicos fuertes a nivel nacional.

Por lo tanto, estos cambios en las aguas podrían guardar relación con la interacción entre el flujo y el medio poroso o fracturado de la roca debido al aporte químico/mineralógico de las paredes en los conductos preferentes o bien como un resultado netamente físico por fuertes cambios en la hidráulica del medio rocoso vinculados con estrechamientos o nuevas aperturas asociadas implicando una evidente complejidad en los sistemas acuíferos locales del área de estudio.

Por otra parte, el posible leve hidrotermalismo identificado en las aguas del manantial de las "Las Cuatro Fuentes" dentro de la interpretación geológica propuesta, implicaría la posibilidad de una leve interacción local de flujos geotérmicos o hidrotermales profundos y/o distales que pueden ascender por convección térmica debido a la permeabilidad secundaria (fracturamiento) por el fuerte tectonismo en el área de estudio (ej. Sistema de Fallas Navarro). Lo anterior no solo aportaría masa o quimismo si no también energía traducida en leves aumentos de temperatura para la mezcla final de aguas surgentes en los manantiales ubicados en la base del supuesto cerro/volcán Santa Lucía.

Lo antes mencionado explicaría el enriquecimiento químico (ej. con sulfatos) de las aguas y por tanto su sabor así como el leve termalismo las aguas en el manantial precitado (Figura 11), siendo un aspecto previamente observado por Sanabria (2014), como una condición geológica regional que permite la aparición de procesos geotérmicos de baja entalpía tales como los existentes, no muy lejos del área de estudio, en el sector del valle de Orosí, Aguacaliente de Cartago y lugares aledaños. 


\section{Tectónica y sismicidad asociadas con posibles procesos lumínico/ calóricos en los alrededores del supuesto cerro o volcán Santa Lucía}

Como se mencionó anteriormente las estructuras tectónicas (fallas) o alineamientos asociados, como los observados en el área de estudio, pueden propiciar condiciones geológicas especiales de fuerte compresión o esfuerzos así como de deformación de diferente grado en los materiales litológicos, lo cual bajo condiciones y características geológicas, físicas y composicionales, muy particulares, podrían haber permitido la aparición de fenómenos naturales, poco observados, pero que el United States Geological Survey (USGS) (2019) define como luces de terremoto o también conocidas, en inglés, como "Earthquake Lights" (EQL en inglés).

Para Thériault et al., (2014), un rasgo característico de las luminosidades sísmicas o luces de terremoto es que la mayoría de estas se ven antes y/o durante un terremoto, pero raramente después de la liberación y disipación de la energía del estrés sísmico en la corteza, lo cual concuerda muy bien con el relato de Prado (1921) en la "Leyenda de las Cuatro Fuentes".

Adicionalmente Fidani (2010), incluye como parte de estos fenómenos naturales la aparición de columnas de fuego, flamas, bolas de fuego, pequeñas flamas, vapores/ nubes luminosas difusas y rayos de fuego con colores que iban del amarillo, naranja y el rojo además de presencia, en algunos casos, de descargas eléctricas, descripciones muy similares a lo indicado por Prado (1921) en sus relatos.

Por otra parte, en una experiencia narrada por la señora M. Coto en compañía de otras personas, se describen características parecidas a las citadas en el libro de Prado (1921), sobre fenómenos lumínicos muy similares, para un día del mes de octubre de 1964 aproximadamente a las 5 am a un kilómetro al NO del supuesto cerro, en un sector de posible correlación neotectónica; no obstante, sin sismicidad reportada (comunicación personal, 10 de noviembre, 2015).

Bajo esta suposición sobre el posible sismo o terremoto, con un posible epicentro cercano al valle de Ujarrás, que pudo ocasionar estos fenómenos, se puede considerar todos aquellos eventos históricos con un registro dentro de la época colonial de Costa Rica, tomando como referencia a Peraldo \& Montero (2007), los cuales señalan los sismos fuertes o terremotos, con intensidades sísmicas aproximadas en paréntesis, que tuvieron afectación directa en la ciudad colonial de Cartago en los años: 
1678 (VII), 1715 (VI+), 1727 (VI+), 1728 (VI+), 1756 (VII-VIII?), 1794 (VI+-VII) y 1821 (VI+), mismos que pueden servir como una posible referencia de la actividad sísmica colonial y geoespacialmente cercana al área de estudio.

En resumen, es mediante la integración coherente y el análisis de las características del contexto fisiográfico en su conjunto (Figura.11), que se logra identificar, de forma convergente, un factor común ligado con el tectonismo local como el elemento fisiográfico medular de la presente interpretación geológica vinculada con las leyendas de Prado (1921) sobre el aparente cerro/volcán Santa Lucía.

Por lo tanto, mediante la presente interpretación geológica se descarta una actividad volcánica histórica y localmente reciente en el área de estudio, como la causa principal de los aparentes fenómenos descritos por Prado (1921) para las leyendas del cerro/volcán Santa Lucía en el valle de Ujarrás; no obstante, cabe resaltar que todas estas leyendas aportan el valor geográfico necesario dentro de la parte narrativa de fenómenos y sucesos, para facilitar la formulación de la presente interpretación geológica así como de las siguientes investigaciones que se puedan derivar en el futuro.

\section{Referencias}

Archivo Nacional de Costa Rica (ANCR). (2020). Álbum de Figueroa con la Cuadrícula de la Villa de Ujarrás, 1824 [https://www.archivonacional.go.cr/index.php?option $=$ com $\_$phocagallery\&view $=$categor y\&id=56:59-74\&Itemid=144].CR-AN-AH-JMFIGOR-ALBUM. Plano de la villa de Ujarrás en 1824. 1-063f.

Barrantes, M. (2011). Reportes de análisis petrográfico de rocas ígneas de las muestras: P0-1B, P08, P10 y P15. Instituto Costarricense de Electricidad. [reporte interno]. 8 págs

Benavides, M. (1999). De Ujarrás a Paraíso: análisis del traslado de una población 1821-1850. (Tesis de licenciatura). Universidad de Costa Rica, p. 387.

Bemis, K., Walker, J., Borgia, A., Turrin, B., Neri, M. \& Swisher, C. (2011). The growth and erosion of cinder cones in Guatemala and El Salvador: Models and statistics. Journal of Volcanology and Geothermal Research 201, pp. 39-52. 
Bergoeing, J. \& Malavassi, V. (1981a). Carta geomorfológica del valle central de Costa Rica. Hoja Tapantí 1:50 000 Map 3445 -III. Ed. Inst. Geof. Nac. Costa Rica.

Bergoeing, J. \& Malavassi, V. (1981b). Carta geomorfológica del valle central de Costa Rica. Hoja Istarú \# 3445 IV, escala 1:50000. Ed. Inst. Geof. Nac. Costa Rica.

Bolaños, R., Quirós, M., Alvarado, S., Quirós, E., Orozco, C., Solano, J. \& Rojas; C. (1993). Ayer Ujarrás, hoy Paraíso. Ed Servitex Flores, Universidad de Texas, p. 299.

Brenes, V. (2018). La devoción a Nuestra Señora de la Pura y Limpia Concepción del Rescate de Ujarrás: Un estudio de la mentalidad religiosa en Costa Rica: 1593-1852. Universidad de Costa Rica. Tesis sometida a consideración de la Comisión del Programa de Posgrado en Historia para optar por el título de Maestría Académica en Historia, p. 340.

Campos, M. \& Orozco, D. (2011). Villa de Ujarrás: una propuesta desde la arqueología para analizar la dinámica socioeconómica en Costa Rica desde finales del siglo XVI hasta inicios del siglo XIX. Universidad de Costa Rica. Tesis para optar por el grado de Licenciatura en Antropología con énfasis en Arqueología, p. 260.

Chaves, R. (2010). Informe de perforación del Pozo TP-47. Empresa Santos Limitada, p. 8.

Curewitz, D. \& Karson, J. (1997). Structural settings hydrothermal outflow: Fracture permeability maintained by fault propagation and interaction. Journal of volcano logy and geothermal research 79, pp. 148-168.

Custodio, E. \& Llamas, M. (2001). Hidrología Subterránea. Ed. Omega, Barcelona, España. 2350 págs.

Denyer, P., Montero, W. \& Alvarado, G. (2009). Atlas Tectónico de Costa Rica. Costa Rica: Ed. Universidad de Costa Rica. 81 p.

Dóndoli, C. \& Torres, A. (1954). Estudio Geoagronómico de la Región Oriental de la Meseta Central.- Min. Agricultura e Ind., San José. 180 págs.

Fidani, C. (2010). The earthquake lights (EQL) of the 6 April 2009 Aquila earthquake, in Central Italy Nat. Hazards Earth Syst. Sci., 10, pp. 967-978, [www.nat-hazards-earth-syst-sci.net/10/967/2010/ doi: http://dx.doi.org/10.5194/nhess-10-967-2010]. 
Giggenbach; W. (1988). Geothermal solute equilibria. Derivation of Nak-Mg-Ca. geoindicators. Geochimica et Cosmochimica Acta, 52, 2749-2765.

Giggenbach, W. \& Goguel, R. (1989). Collection and analysis of geothermal and volcanic water and gas discharges. Report No. CD 2401. Department of Scientific and Industrial Research. Chemistry Division. Petone, New Zealand.

González, C. (1910). Temblores, terremotos, inundaciones y erupciones volcánicas en Costa Rica 1608-1910. 239 págs., San José: Tipografía de A. Alsina, 1910. Reimpresión Editorial Tecnológica, Cartago, Costa Rica 1994.

Instituto Costarricense de Electricidad (ICE). (2011-2012). Reporte de resultados químicos de muestras de agua BE-42. BE-40b y BE-42b. [reporte interno] $2 \mathrm{p}$.

JAXA/METI. (2011). ALOS PALSAR Hi-Res Terrain Corrected 2011 (AP 26652 FBS F0190 RT1). Accedido a través de ASF DAAC [https://www.asf.alaska.edu] el 3 febrero 2019. DOI: http://dx.doi. org/10.5067/Z97HFCNKR6VA.

Krushensky, R. (1972). Geology of the Istarú Quadrangle, Costa Rica. Geological Survey Bulletin 1358. - 46 p.

Linkimer, L. (2002). Intensidades del sismo de Bijagua de Upala ( $m w=$ 5,4), 27 de enero del 2002. Instituto de Investigaciones en Ingeniería, Laboratorio de Ingeniería Sísmica, Universidad de Costa Rica, 10 p. Montero, W., Linkimer, L. \& Rojas, W. (2016). El Sistema de Falla Navarro: desplazamientos izquierdos a lo largo del cinturón deformado del centro de Costa Rica. Revista Geológica de América Central 55, 71-100, 2016 DOI: http://dx.doi.org/10.15517/rgac.v55i0.27062 ISSN: 0256-702.

Mora, G. (1998). Ujarrás de doctrina indígena a Villa Mestiza. Compiladores: Bozzoli de Wille, M. E., Barrantes, R., Obando, D., \& Rojas, M. (1995). Memorias de I Congreso cientifico sobre pueblos indígenas de Costa Rica y sus fronteras. San José, Costa Rica: Editorial de la Universidad de Costa Rica. 504 págs.

Nicholson, K. (1993). Geothermal fluids- Chemistry and exploration techniques. - 263págs.Springer-Verlag Berlín Heidelberg New York. 
Obando, L. (2004). Mega-rasgos geomorfológicos del modelo de elevación digital, asociados al Volcán Barva. Revista Geológica de América Central, 3, 81-86, ISSN: 0256-7024.

Ortiz, E. \& Montoya, C. (2014). Atlas Digital de Costa Rica 2014 [CD-ROM]. Instituto Tecnológico de Costa Rica. Escuela de Ingeniería Forestal.

Peraldo, G. \& Montero, W. (2007). Temblores documentados para el periodo colonial de Costa Rica. Revista Geológica de América Central, 36 Especial, 25-47.

Powell, T. \& Cumming W. (2010): Spreadsheets for geothermal water and gas geochemistry In: Proccedings of Thirthy-Fifth Workshop on Geothermal Reservoir Engineering, Stanford University, Stanford, California, February 1-3, 2010.

Prado, E. (1921). Nuestra Señora de la Virgen de Ujarrás. 3 ed. San José, Costa Rica: Costa Rica.

Quirós, T. (1981). Ujarrás. San José: Editorial Costa Rica.págs.80

Sanabria, I. (2014). Propuesta de modelo conceptual geotérmico de baja entalpia para el Valle de Orosí, Paraíso, Cartago, Costa Rica - San José, Costa Rica: Escuela de Geología-UCR, 2014 - 146 páginas.

Schoeller, H. (1962). Hydrologie dynamique et chemique, Recherche, Explotation et evaluation des resources. - 642 págs Manson et cie editeurs.

Sistema Nacional de Información Territorial (SNIT). (2020). Infraestructura Nacional de Datos Espaciales de Costa Rica. Recuperado de: www.snitcr.go.cr.

Sojo, D., Denyer, P., Gazel, E. y Alvarado, G. (2017). Geología del cuadrante Tapantí (1:50 000), Costa Rica. Revista Geológica de América Central, 56: 83-116, Doi: http://dx.doi.org/10.15517/rgac. v0i56.29238.

Sojo, D. (2018). Geología de la hoja Paraíso (1:10 000), Costa Rica. Revista Geológica de América Central, 59, 101-124, 2018 doi: http:// dx.doi.org/10.15517/rgac.v59i0.34161 ISSN: 0256-7024.

Thériault, R., ST-Laurent, F., Freund, F. T., And Derr, J. S. (2014). Prevalence of Earthquake Lights Associated with Rift Environments. Seismological Research Letters, 85, no. 1, 159-178. doi: http://dx.doi. org/10.1785/0220130059.

United States Geological Survey. (USGS) (2019). What are earthquake lights? Accedido a través de https://www.usgs.gov/faqs/ 
what-are-earthquake-lights?qt-news_science_products=0\#qtnews_ science products el 24 de febrero de 2019.

Valenzuela, E. (2011). La leyenda: un recurso para el estudio y la enseñanza de la Geografía. I Revista de Investigación de la Universidad Simón Bolívar, ISSN-e 1665-692X, № 10.

Vargas, A. (2016). Influencia del sismo de golfito del 30 de julio de 2002 (Mw 6,2) sobre una prueba de bombeo en el acuífero confinado del sitio de presa del P.H. Pirrís, Costa Rica. Revista Geológica de América Central 54, 143-153, 2016 DOI: http://dx.doi.org/10.15517/ rgac.v54i0.21151 ISSN: 0256-7024.

Vázquez, E. \& Serrano, A. (2012). Software EASY_QUIM v.5.0 del Grupo de Hidrología Subterránea (GHS) del Departamento de Ingeniería del Terreno de la Unidad Politécnica de Catalunya (UPC). https://h2ogeo.upc.edu/es/investigacion-hidrologia-subterrania/ software/42-easy-quim el 20 de mayo de 2019.

Villa, V. (2013). Morfología de estructuras volcánicas cenozoicas de los andes centrales entre los $25^{\circ}$ y $26^{\circ} \mathrm{s}$, Chile. Memoria para optar al título de geólogo. Facultad de Ciencias Físicas y Matemáticas. Departamento de Geología. Universidad de Chile 97 págs.

Zuidam, R. (1986). Aerial photo-interpretation in terrain analysis and geomorphologic mapping; with contributions from F.I. van ZuidamCancelado and other members of the International Institute for Aerospace Survey and Earth Sciences (ITC), 442 págs. 
